\title{
Everyone hates a know-all
}

The Last Man Who Knew Everything: Thomas Young, the Anonymous Polymath Who Proved Newton Wrong, Explained How We See, Cured the Sick, and Deciphered the Rosetta Stone, Among Other Feats of Genius

by Andrew Robinson

Pi Press: 2006.288 pp. $€ 17.99$

\section{David Philip Miller}

Know-alls can be maddening. Polymathy, however fascinating, may be a vice as much as a virtue in this age of specialization. In his book The Last Man Who Knew Everything, Andrew Robinson attempts only an introduction to the life of the polymath Thomas Young (1773-1829) - a full biography of 'Phenomenon Young, as he became known, would have required a team of specialists.

Robinson aims to introduce Young's life and achievements to a broad audience, and his readability quotient is high. The book is a superior example of the recent flood of popular works on the history of science and technology no doubt inspired by the success of Dava Sobel's Longitude (Walker, 1995). Robinson frequently tells us how remarkable Young's achievements were and defends him from Young's contemporaries who found him obscure, difficult and, yes, maddening. Robinson's parting shot is to compare Young to Leonardo Da Vinci. However, the hyperbole is balanced by Robinson's genuine interest in why Young was not universally admired, and why he has received a mixed press from specialist historians. The meditations on specialization this induces are interesting but, in $\mathrm{my}$ view, fall short of explaining the negative reactions to Young.

Young came from a Quaker family who recognized his precocity early. Tutors and schoolmasters fed his hunger for languages - by his teens he spoke Greek and Latin, and had a working knowledge of Hebrew, Chaldee, Syriac, Samaritan and Persian. He taught himself mathematics and natural philosophy before attending medical lectures in London and studying at the universities of Edinburgh, Göttingen and Cambridge. He became a fellow of the Royal Society at the age of just 21.

Best known for his work on the interference of light and the development of a wave theory in opposition to the prevailing newtonian corpuscular ideas, Young also made crucial contributions to understanding the physiology of the eye and vision. In 1814 he began to decipher the demotic and hieroglyphic inscriptions of the Rosetta Stone, but his important contributions were overshadowed by JeanFrançois Champollion's subsequent efforts. Beyond this, Young's versatility knew few bounds, as shown by his numerous contributions to the Encyclopaedia Britannica and his published lectures on natural philosophy and the mechanical arts. Young's profession was medicine but his practice was not very successful; an inheritance and other sources of income meant that this was not a problem, however. Having abandoned Quakerism, he moved in high social circles in London. Hedied at the age of 56 from pulmonary troubles and, Robinson speculates, intellectual exhaustion.

So why the lack of universal admiration? Personality was an issue: Young comes across as self-contained but self-confident and unlikely to suffer fools. Robinson is right, also, in arguing that Young was a victim of a specializing age, of a mixture of envy and disbelief that he could successfully traverse so many fields. However, Robinson fails to consider sufficiently the social and intellectual context of the learned world of the metropolis in which Young grew to maturity. In the 1820 s, new cultural patterns were pitched against the old. In the old pattern, Young's range of activities was not unusual, except in the success that he enjoyed. He was one of a type - a medical doctor, versed in classics and natural philosophy, and interested in antiquities. In fact these were the very people that specializing (but hardly specialist) young Turks fought against in the 1820 s as they challenged the existing power structures of science in the Royal Society and elsewhere. This can explain much of the hostility towards Young when he was foreign secretary of the Royal Society, secretary of the Board of Longitude, and editor of The Nautical Almanac. Pushy young Cambridge scholars welcomed Young's advocacy of wave theory but were exasperated by his mathematical obscurity. Along with their astronomical allies in London, they sought to reform (not abolish, as Robinson has it) the key astronomical institutions in which Young represented, culturally and temperamentally, the old guard.

Greater awareness of this institutional and cultural context would have lifted the narrative above being an encomium to Young, insightfully placed as it is against the backdrop of the generic problem of specialization. Discerning exactly what specialization meant in early nineteenth-century Britain is important to understanding why this particular know-all was so maddening as well as an object of justified admiration. Young was truly remarkable, but was also a creature of his times, not a Colossus astride them.

David Philip Miller is associate professor of

history and philosophy of science at the University of New South Wales, Sydney, New South Wales 2052, Australia.

\section{Life, the Universe and entropy}

\section{Decoding the Universe: How the New \\ Science of Information is Explaining \\ Everything in the Cosmos, From our Brains to Black Holes \\ by Charles Seife \\ Viking: 2006.288 pp. $\$ 24.95$}

\section{Robert J. McEliece}

Near the end of his new book Decoding the Universe, Charles Seife argues with a straight face that there exists a universe parallel to ours that is populated by a race of superintelligent octopuses. The funny thing is, I believed him.

If Douglas Adams had not already used it, a more appropriate title would have been Life, the Universe and Everything for that is in fact just what this book is about. Seife tells us that the modern science of 'information theory' (I'll explain the quotation marks below) implies that everything in the Universe, including life, is part of a vast cosmic war between the forces of good (information) and evil (entropy), with entropy the predestined winner. To support this disturbing hypothesis, he weaves a wide-angled interdisciplinary narrative with chapters on cryptography, thermodynamics, classical information theory, genetics, relativity,

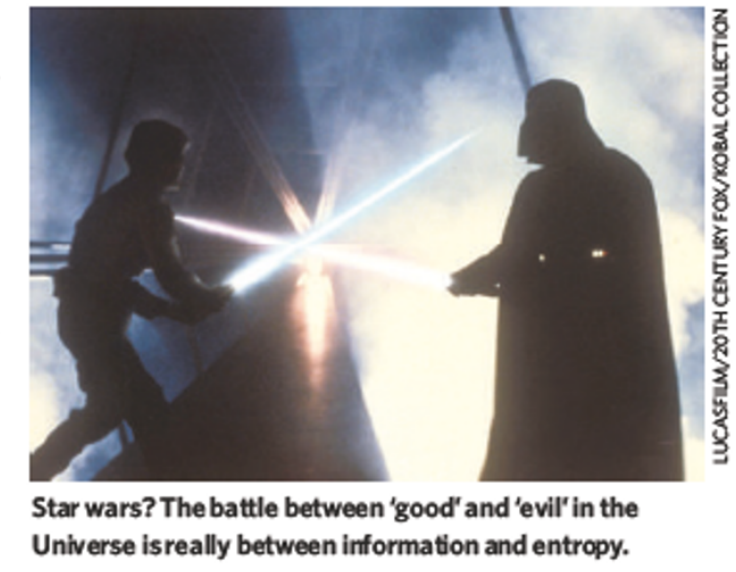

Star wars? The battle between 'good' and 'evil' in the Universe is really between information and entropy. quantum mechanics, quantum information theory and cosmology (puzzlingly, string theory is absent). Each of these topics is a major scientific discipline, and Seife seems to have mastered them all.

Taking centre stage throughout the book is Claude Elwood Shannon (1916-2001). Shannon was a brilliant US mathematicianengineer who worked at Bell Labs and in 1948 invented a set of mathematical tools to solve what he called the fundamental problem of communication: "that of reproducing at one point either exactly or approximately a message selected at another point ${ }^{\text {. }}$ Seife omits any 
mention of Shannon's most celebrated result, the 'noisy-channel coding theorem,' emphasizing instead Shannon's notion of entropy, the mathematical measure of information and, paradoxically, disorder. Shannon's initial work was indeed called 'information theory', but engineers, mathematicians and physicists today use the term to mean quite different things. I am an information theorist-communication engineer by trade, but Seife's information theory is a branch of physics, and much of the 'information theory' he discusses is very far from communication engineering.

The text is filled with interesting and quirky personalities. In the early chapters, we read of two suicides (Ludwig Boltzmann and Alan Turing) and a guillotining (Antoine-Laurent Lavoisier), but then suddenly all the biographical details stop. I would have liked to see a bit more about the human side of celebrated intellectuals such as Einstein, Richard Feynman, Stephen Hawking and Shannon, but never mind. According to Seife, in the cosmic war between information and entropy, the individual doesn't matter.

The technical and psychological weight of the material is lightened throughout by the author's unfailing sense of humour, and as homework I assign the reader to locate, somewhere in the text: a scatological remark about McDonalds; a gratuitous wisecrack about the animal-rights group PETA; a discussion about the wisdom of using the Starship Enterprise's transporter beam; and a discussion of the difficulty of getting a cat into a bra.

Finally, potential readers should be warned that this is a non-technical book about some very, very technical material. There is only one equation in the text (apart from footnotes and appendices), which makes it accessible to a non-mathematical audience but sometimes forces Seife into intricate verbal gymnastics and paradoxes. Indeed, at times Seife seems to doubt his own material, and the book is rife with unscientific adjectives such as absurd, bizarre, confusing, hairy, horrible, insane, ridiculous, sloppy, spooky and just plain weird. (To be fair, the term 'spooky' is bone fide quantum-mechanical technical jargon, as in 'spooky action at a distance.) By the last chapter, Seife has begun referring to celestial coin flips, god-like beings and supernatural creatures (there are no atheists in black holes, it seems). Still, it will be a rare reader, professional scientist or not, who fails to be entertained and informed by this well-written grand-daddy of all ghost stories.

RobertMcEliece is in the Department of Electrical Engineering, California Institute of Technology, Pasadena, California 91125, USA.

\section{Form becomes feeling}

\section{Siobhan Davies looks to science to shape her dance.}

\section{Martin Kemp}

Why does Siob han Davies expose her dancers to an informal acadermy of thinkers from diverse worlds, including science and medicine? The answer lies in the depth and power of our instinctive response to body language - a response thatchoreographers and dancers are adept at exploiting - and her desire to reconstitute and refresh its stock vocabulary.

Her idea is to unsettle the automatic habits and patterns of our responses, especially those involved with dance, refreshing our perceptions by refreshing theirs. The wonder of the complexity of familiar acts, something we take for granted, emerges anew.

For her current programme, In Plain Clothes, performed recently in her own stunning dance space and now touring England, she drew in a set of luminaries for her academy. Most notable are the architect Sarah Wigglesworth, the heart surgeon Francis Wells (see Nature 429, 19; 2004), the linguist Susan Hitch and the landscape designer Dan Pearson.

Davies and her dancers witnessed one of Wells's operations. There was no set agenda and no set outcome, other than to promote new shared and individual insights into the human body. The dancers, who are immersed daily in the physical process of dance as a kind of athletic performance, were jolted into a world of new perceptions and thoughts.

The dancers were impressed by the profound stillness of the limbs, torso and head of the anaesthetized patient during the

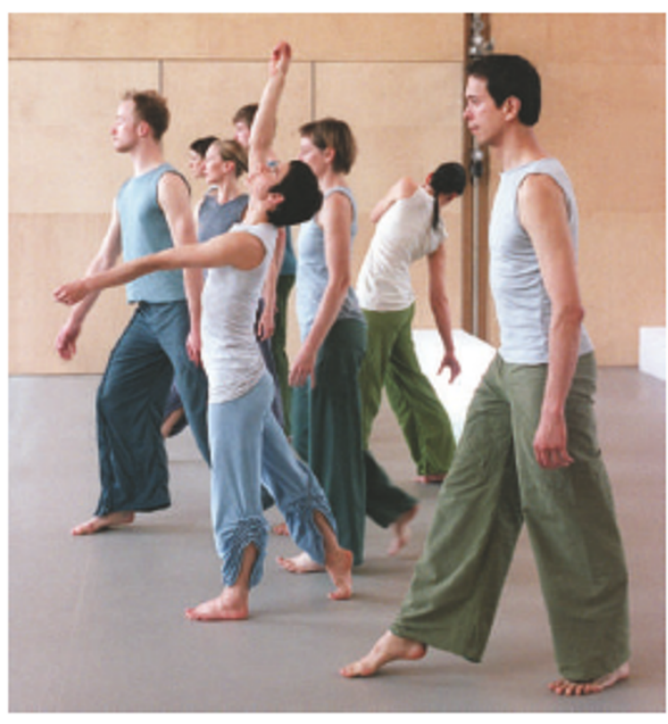

separately to assign a movement to each note. This surprisingly literal approach is intended, Davies declares, "to cut outall the fat". It also introduces a random element that sets a challenge for the subsequent ordering of the dancers as an ensemble.

What follows is a phase in which disorder and order fight for formal dominance. There is a process akin to the self-organization of a complex physical process as it settles into a pattern, with the important qualification that intentional choices here guide the emergence of certain orders.

The process is in essence highly formal and abstract. The final result is highly structured, centring on a line of dancers walking laterally across the performance space, casting off and

operation, while the surgeon and his team acted out their own choreographed moves. A heart operation is a highly technical performance, like a dance, but it also has deep emotional resonance for those who bear witness to a life saved. It serves as an analogy for the relationship of form to emotion in dance.

There is also an element of unpredictability in every operation. Davies' work thrives on the confrontation between control and the unpredictable, between imposed order and the unexpected.

InPlain Clothes - the title conveys the direct and unadorned nature of the dance, costumes and setting - began with the structured score of Italian folk songs in a composition by Matteo Fargion. Each dancer was given one of the tunes and asked re-absorbing pairs and larger numbers of virtuoso dancers as the piece progresses.

Structure "releases invention", Davies says. Here it creates trigger points at which emotion is released. As in a sonnet, the fourbar blues and folk songs, it is the tightness of the form that allows our perception of the exceptional. Body language works like this in everyday life, with the unexpectedsomething that departs from the anticipated pattern - jolting us into another level of awareness.

The songs in the piece are aboutmemory, the familiar, departure and loss. Davies does not literally tell their stories. But sheuses form as a vehicle to convey the deep elements of their emotional charge. Martin Kempis professor of the history of art at the University of Oxford, Oxford OX1 1PT, UK. 